\title{
Characteristics of contractile activity in the renal artery of ovariectomized rats
}

\author{
Budbazar ENKHJARGAL ${ }^{1,2}$, Michio HASHIMOTO ${ }^{2}$, Hiroki KINOSHITA ${ }^{1}$ and \\ Yasushi SAKAI ${ }^{1,3}$ \\ ${ }^{1}$ Division of Physiology, Department of Occupational Therapy, School of Nursing and \\ Rehabilitation Sciences, Showa University, Japan \\ ${ }^{2}$ Department of Environmental Physiology, Shimane University School of Medicine, Japan \\ ${ }^{3}$ Present address: Laboratory of Physiology and Pharmacology, Department of Physical \\ Therapy, Faculty of Health Science Technology, Bunkyo University, 1196 Kamekubo, \\ Fujimino-shi, Saitama 356-8533, Japan
}

Received December 25, 2007; Accepted January 10, 2008

\begin{abstract}
The incidence of cardiovascular disease is markedly lower in cycling, pre-menopausal women and post-menopausal women receiving estrogen than in men or untreated postmenopausal women. Clinical studies demonstrate a protective role of estrogen in hormone replacement therapy in terms of reducing cardiovascular risk. However, the benefits of hormone replacement therapy in cardiovascular disease remain unclear. We investigated the effects of estrogen on the contractile responses of the renal artery of ovariectomized Wistar rats (OVX) compared to both ovariectomized $17 \beta$-estradiol-treated rats (OVXE) and sham-operated (control) rats. Isometric contraction of renal artery was recorded with a strain gauge transducer. The maximum contractile response of the renal artery smooth muscle to $\mathrm{KCl}(80 \mathrm{mM})$ in the OVXE group was significantly higher than that in both the control and OVX groups. The phenylephrine (PE) concentration-response curves in all three groups indicated a greater sensitivity at lower concentrations of $\mathrm{PE}$ following treatment with $100 \mu \mathrm{M}$ L-arginine methyl ester (L-NAME). The $\mathrm{EC}_{50}$ values for $\mathrm{PE}$ in the three groups were 2 times lower in the presence of L-NAME than those lacking exposure to L-NAME. The $\mathrm{EC}_{50}$ value for $\mathrm{PE}$ in the OVX group was $\sim 3$ times lower in the presence of L-NAME than in those lacking exposure to L-NAME and $100 \mathrm{nM}$ BMY 7378, an $\alpha_{1 D}$-adrenoceptor antagonist. The rate of relaxation of the PE-induced contraction $\left(\mathrm{T}_{1 / 2}\right)$ was significantly reduced in the OVX group relative to both the control and OVXE groups. $\mathrm{T}_{1 / 2}$ values after treatment with $100 \mu \mathrm{M} \mathrm{L}$-NAME were slower than those lacking exposure to L-NAME in all groups. Further, the $\mathrm{T}_{1 / 2}$ value of the OVX group was 2 times greater than that of the control; this change was reversed in the OVXE group. In conclusion, our results suggest that estrogen regulates contraction and relaxation in the renal artery via $\mathrm{NO}$ synthase activity and alteration of the $\mathrm{Ca}^{2+}$ transport systems.
\end{abstract}

Key words: renal artery, ovariectomy, $\mathrm{Ca}^{2+}$ regulation, $\mathrm{NO}$ synthase

Correspondence to: Yasushi Sakai, Ph.D., Professor, Laboratory of Physiology and Pharmacology, Department of Physical Therapy, Faculty of Health Science Technology, Bunkyo University, 1196 Kamekubo, Fujimino-shi, Saitama 356-8533, Japan

Phone: +81-49-261-7913 Fax: +81-49-261-8923 e-mail: ysakai@hst.u-bunkyo.ac.jp 


\section{Introduction}

The incidence of cardiovascular disease is markedly lower in cycling, pre-menopausal women and post-menopausal women receiving estrogen than in men or untreated postmenopausal women. Clinical studies support a protective role of estrogen in hormone replacement therapy in terms of reducing cardiovascular risk. Further, recent studies have demonstrated the benefits of hormone replacement therapy in cardiovascular disease (REF). However, an advisory from the American Heart Association did not recommend initiation of hormone replacement therapy for the sole purpose of preventing cardiovascular disease (Hulley et al., 1998; Tolbert et al., 2001).

It has been reported that nitric oxide (NO) release and NO synthase activity are enhanced by estrogen in the uterine arteries but not in the renal arteries of non-pregnant sheep (Vielle $e t$ $a l ., 1996)$. In contrast, $17 \beta$-estradiol antagonizes increases in vascular tone in hypertensive females by enhancing NO-dependent relaxation and by suppressing endothelium-derived contractile factor (EDCF)-mediated mechanisms in an NO-independent manner (Zhang et al., 2002). Estrogen pretreatment of male dogs decreased both maximum contractile responses and $\mathrm{EC}_{50}$ value to $\mathrm{U} 46619$ (a TXA 2 mimetic) or PE in the coronary artery. These results suggested that smooth muscle reactivity of the dog coronary artery to both U46619 and PE might be susceptible to regulation by both androgens and estrogens (Karanian et al., 1996). Changes in the vasomotor reactivity of renal arteries may similarly be altered by changes in the hormonal milieu and lead to defective autoregulation of renal hemodynamics. However, the exact contractile activity in renal arteries isolated from ovariectomized rats (OVX) remains unclear. This study examined whether estrogen altered phenylephrine (PE) contraction and the involvement of $\mathrm{NO}$ and $\mathrm{Ca}^{2+}$ regulation in the renal arteries isolated from OVX.

\section{Materials and methods}

All protocols involving animals were approved by the Animal Care and Use Committee of Showa University, Japan. Six week-old female Wistar rats were purchased from Japan Laboratory Animals, Inc., (Tokyo) and housed under a 12:12-h light-dark cycle; food and water were available ad libitum. At eight weeks, rats were randomly divided into three groups. Two groups were ovariectomized and the third group underwent a sham operation. After four weeks post-surgery, one of the ovariectomized groups (OVXE) was implanted subcutaneously with a silicone capsule (Osmotic pump MODEL 2ML2, Alzet, USA) containing 17 $\beta$-estradiol (17 $\mu \mathrm{g}$ ). The animals in the remaining group of ovariectomized (OVX) rats and the "sham" operated rats (controls) were all implanted with a placebo pellet. Two weeks post-implantation, animals were anesthetized with diethyl ether and euthanized by decapitation and their kidneys with intact renal arteries were quickly removed for dissection of the arteries. The weight of the body, of the abdominal fat and of the wet uterine were measured to verify estrogen treatment.

\section{Contractile studies of isolated renal arteries}

Freshly isolated kidneys with their attached renal artery were immediately placed in Krebs- 
Henseleit Buffer solution (KHB) containing $118 \mathrm{mM} \mathrm{NaCl}, 4.5 \mathrm{mM} \mathrm{KCl}, 2.5 \mathrm{mM} \mathrm{CaCl}, 1.2 \mathrm{mM}$ $\mathrm{KH}_{2} \mathrm{PO}_{4}, 1.5 \mathrm{mM} \mathrm{MgSO}, 25 \mathrm{mM} \mathrm{NaHCO}$ and $11 \mathrm{mM}$ glucose and bubbled with $95 \% \mathrm{O}_{2}-5 \% \mathrm{CO}_{2}$. Ring preparations (length, $2.5-3.0 \mathrm{~mm}$ ) of the main renal arteries were isolated from both kidneys under the dissecting microscope. Once the preparation was isolated, adherent fat tissue was removed from the vessels. The cleaned specimens were placed in a chamber (UFER, Medical Kishimoto, Tokyo, Japan) containing KHB at $37 \pm 0.5^{\circ} \mathrm{C}$ and gassed with $95 \% \mathrm{O}_{2}-5 \%$ $\mathrm{CO}_{2}$. Two fine tungsten wires (100 $\mu$ m diameter) were passed through the lumen of the artery. One end of each wire was connected to an isometric transducer (T7-8-240, Orientec, Tokyo, Japan), whereas the opposite end was attached to the holder; subsequently, isometric tension was recorded on a polygraph (RECTIGRAPH-8K, San-Ei, Tokyo, Japan). Experiments were monitored via computer-based analysis using Mac-Lab and Chart 3.6 software.

The arterial ring preparations were loaded to a tension of $1 \mathrm{~g}$ and allowed to equilibrate for $60 \mathrm{~min}$ in $\mathrm{KHB}$ maintained at $37 \pm 0.5^{\circ} \mathrm{C}$, pH 7.4; subsequently, specimens were bubbled with $95 \% \mathrm{O}_{2}-5 \% \mathrm{CO}_{2}$. During the equilibration, the ring preparations were washed with $\mathrm{KHB}$ every 15-20 min. After equilibration, preparations were contracted with $100 \mathrm{mM} \mathrm{KCl}$, followed by washing with $\mathrm{KHB}$ three times. After $30 \mathrm{~min}$, vessels were again contracted with $60 \mathrm{mM} \mathrm{KCl}$ in order to establish the control level. The $60 \mathrm{mM} \mathrm{KCl}$-induced contraction served as a standard contractile response for each agonist concentration.

\section{Fatty acid composition of uterus and aorta}

The uterus and aorta from each animal were stored at $-80^{\circ} \mathrm{C}$ by flash-freezing in liquid $\mathrm{N}_{2}$ until use or immediately homogenized in ice-cold $0.32 \mathrm{~mol} / \mathrm{L}$ sucrose buffer ( $\mathrm{pH} 7.4$ ) containing $2 \mathrm{mmol} / \mathrm{L}$ EDTA, $0.5 \mathrm{mg} / \mathrm{L}$ leupeptin, $0.5 \mathrm{mg} / \mathrm{L}$ pepstatin, $0.5 \mathrm{mg} / \mathrm{L}$ aprotinin, and $0.2 \mathrm{mmol} / \mathrm{L}$ phenylmethylsulfonyl fluoride using a Polytron homogenizer (PCU 2-110, Kinematica, Lucerne, Switzerland). The homogenates were also stored at $-80^{\circ} \mathrm{C}$ in liquid $\mathrm{N}_{2}$ until use.

Fatty acid composition was determined to estimate the $17 \beta$-estradiol effect on the uterus and the aorta using the one-step chromatographic analysis of Lepage and Roy (1986) described previously (Hashimoto et al., 1999). The protein concentration was estimated using the method of Lowry et al. (1951).

\section{Drugs}

L-phenylephrine hydrochloride, $\mathrm{N}^{\mathrm{G}}$-nitro L-arginine methyl ester (L-NAME), leupeptin, pepstatin, aprotinin, and phenylmethylsulfonyl fluoride were purchased from Sigma-Aldrich (St. Louis, MO, USA). BMY7378 (8-[2-[4-(2-methoxyphenyl)-1-piperazinyl]ethyl-8azaspiro[4.5]decane-7,9-dione dihydrochloride) was acquired from Funakoshi (Tokyo, Japan). All other chemicals and materials were used at the highest grade commercially available.

\section{Statistical analyses}

Analysis of data was conducted with SPSS statistical analysis software (Version 12.0; SPSS Inc, Tokyo, Japan). Results were expressed as the mean \pm SEM. Baseline comparisons between the 3 groups were performed using one-way ANOVA, and post hoc analyses were performed with the Turkey test for two independent samples. Group means were compared 
Table1. Average weights of body, uterus and abdominal fat in the three groups

\begin{tabular}{lccc}
\hline $\begin{array}{l}\text { Groups } \\
\text { weight }(\mathrm{g})\end{array}$ & $\begin{array}{c}\text { Control } \\
(\mathrm{n}=11)\end{array}$ & $\begin{array}{c}\text { OVX } \\
(\mathrm{n}=12)\end{array}$ & $\begin{array}{c}\text { OVXE } \\
(\mathrm{n}=12)\end{array}$ \\
\hline Body & $232 \pm 10$ & $285 \pm 17^{*}$ & $275 \pm 12^{\star}$ \\
Uterus & $0.5 \pm 0.08$ & $0.1 \pm 0.01^{\star}$ & $0.1 \pm 0.01^{*}$ \\
Abdominal fat & $8.1 \pm 0.7$ & $10.3 \pm 0.9$ & $9.1 \pm 0.6$ \\
\hline
\end{tabular}

Control: sham operated rats; OVX: ovariectomized rats; OVXE: ovariectomized rats with $17 \beta$-estradiol treatment for 2 weeks from 4 weeks after ovariectomy. Values are mean \pm SEM. * Significantly different from control $(P<0.05)$.

Table 2. Fatty acid composition of the uterus (mol\%)

\begin{tabular}{|c|c|c|c|c|c|c|}
\hline $\begin{array}{l}\text { FA } \\
\text { Groups }\end{array}$ & PA & SA & $\mathrm{OA}$ & LA & LNA & AA \\
\hline Control & $28.3 \pm 0.9$ & $16.4 \pm 3.6$ & $18.0 \pm 3.0$ & $19.0 \pm 5.2$ & $0.7 \pm 0.3$ & $11.6 \pm 3.0$ \\
\hline OVX & $27.6 \pm 0.7$ & $6.3 \pm 0.6^{\star}$ & $25.4 \pm 0.6^{\star}$ & $32.1 \pm 0.8^{*}$ & $1.5 \pm 0.1^{*}$ & $3.8 \pm 0.5^{*}$ \\
\hline OVXE & $27.9 \pm 1.0$ & $10.6 \pm 4.3$ & $22.4 \pm 3.5$ & $26.5 \pm 6.0$ & $1.2 \pm 0.4$ & $7.2 \pm 3.5$ \\
\hline Groups & $\mathrm{EPA}$ & $\mathrm{DPA}$ & DHA & $\mathrm{n} 6 / \mathrm{n} 3$ & DHA/AA & \\
\hline Control & $0.3 \pm 0.01$ & $1.3 \pm 0.2$ & $4.2 \pm 0.8$ & $5.1 \pm 1.0$ & $0.4 \pm 0.06$ & \\
\hline OVX & $0.3 \pm 0.02$ & $0.9 \pm 0.1$ & $2.0 \pm 0.2^{*}$ & $7.7 \pm 0.4^{*}$ & $0.5 \pm 0.03$ & \\
\hline OVXE & $0.3 \pm 0.01$ & $1.0 \pm 0.2$ & $3.0 \pm 1.0$ & $6.8 \pm 1.2$ & $0.6 \pm 0.1$ & \\
\hline
\end{tabular}

Values are mean \pm SEM from 6 rats in each group. *, Significantly different from control $(P<0.05) . \quad A A$, arachidonic acid; DHA, docosahexaenoic acid; DPA, docosapentaenoic acid; EPA, eicosapentaenoic acid; FA, fatty acid; LA, linoleic acid; LNA: linolenic acid; OA, oleic acid; PA, palmitic acid; SA, stearic acid; DHA/AA, molar ratio of arachidonic acid and docosahexaenoic acid.

using Student's $t$-test. Unless otherwise noted, a nominal two-sided $P$ value less than 0.05 was utilized to assess significance.

\section{Results}

\section{Characteristics in body, uterus and abdominal fat weights among the three groups}

Compared to that of the control group, the OVX group had a significantly increased body weight, while the OVXE group had also increased in body weight (Table 1). The weight of uterus was substantially decreased in both the OVX and OVXE groups compared to that of the control group. The weight of abdominal fat of the OVX group tended to increase compared to that of the control group, but this tendency was prevented by treatment with $17 \beta$-estradiol. While we could detect significant differences in body and uterine weights in the OVX, the $17 \beta$ estradiol treatment made no difference to the body weight and uterus weight in the OVXE group.

Therefore, we further investigated the fatty acid composition in both the uterus and aorta to explore the effect of $17 \beta$-estradiol on these target organs- the uterus compared to the aorta. The detailed fatty acid composition of both the uterus and the aorta are shown in Table 2 and Table 3 respectively. The major fatty acid composition in the uteri isolated from the OVX animals was 
Table 3. Fatty acid composition of the aorta (mol\%)

\begin{tabular}{|c|c|c|c|c|c|c|}
\hline $\begin{array}{l}\text { FA } \\
\text { Groups }\end{array}$ & PA & SA & $\mathrm{OA}$ & LA & LNA & $\mathrm{AA}$ \\
\hline Control & $28.7 \pm 0.9$ & $15.5 \pm 2.0$ & $20.2 \pm 1.8$ & $22.0 \pm 2.7$ & $0.6 \pm 0.1$ & $8.9 \pm 1.6$ \\
\hline ovx & $31.5 \pm 1.0$ & $15.5 \pm 1.0$ & $19.3 \pm 1.2$ & $21.5 \pm 1.1$ & $0.6 \pm 0.1$ & $8.0 \pm 1.0$ \\
\hline OVXE & $30.3 \pm 1.0$ & $16.3 \pm 2.0$ & $19.0 \pm 1.3$ & $21.0 \pm 2.3$ & $0.6 \pm 0.1$ & $9.1 \pm 1.4$ \\
\hline Groups & $\mathrm{EPA}$ & DPA & DHA & $\mathrm{n} 6 / \mathrm{n} 3$ & DHA/AA & \\
\hline Control & $0.2 \pm 0.02$ & $1.3 \pm 0.2$ & $2.6 \pm 0.2$ & $6.8 \pm 0.7$ & $0.3 \pm 0.03$ & \\
\hline OVX & $0.2 \pm 0.01$ & $1.0 \pm 0.1$ & $2.3 \pm 0.3$ & $7.3 \pm 0.6$ & $0.3 \pm 0.01$ & \\
\hline OVXE & $0.3 \pm 0.01$ & $1.1 \pm 0.1$ & $2.4 \pm 0.2$ & $7.0 \pm 0.6$ & $0.3 \pm 0.01$ & \\
\hline
\end{tabular}

Values are mean \pm SEM from 6 rats in each group. AA, arachidonic acid; DHA, docosahexaenoic acid; DPA, docosapentaenoic acid; EPA, eicosapentaenoic acid; FA, fatty acid; LA, linoleic acid; LNA: linolenic acid; OA, oleic acid; PA, palmitic acid; SA, stearic acid; DHA/AA, molar ratio of arachidonic acid and docosahexaenoic acid.

substantially different from that of the control animals. Concentrations of stearic acid (SA) and arachidonic acid (AA) in the OVX group were $\sim 3$ times less than those in the control (6.3 vs. 16.4 mol\%, $P<0.05$ and 3.8 vs. $11.6 \mathrm{~mol} \%, P<0.05$, respectively). These differences in fatty acid in the OVX animals might be attenuated by treatment with $17 \beta$-estradiol as shown in the OVXE animals. However, there were no differences in the major fatty acid composition in the aorta among the three groups. We also confirmed the effect of treatment with $17 \beta$-estradiol in the OVXE group.

\section{Contractile responses to $\mathrm{KCl}$}

The concentration-response curves for renal artery preparations from both OVX and OVXE rats exhibited a significantly greater increase in the maximum response to $\mathrm{KCl}$. Compared to the control group, the contractile responses of the renal artery preparations to $\mathrm{KCl}$ in the OVXE group was significantly higher at both $80 \mathrm{mM}$ and $100 \mathrm{mM} \mathrm{KCl}$ concentrations, and were $99.1 \pm$ $1.6 \%$ vs. $107.7 \pm 1.9 \%(P<0.05)$, respectively at $80 \mathrm{mM} \mathrm{KCl}$ (Fig. 1). The response to $60 \mathrm{mM} \mathrm{KCl}$ showed no significant difference among the three groups. Therefore, the response to $60 \mathrm{mM}$ $\mathrm{KCl}$ in each group was considered to be the $100 \%$ response when we compared the PE response.

\section{Effects of L-NAME and BMY 7378 on PE concentration-responses}

The PE concentration-response curve of the OVX group was shifted to the left compared to that of the control group (Fig. 2A). In addition, the $\mathrm{EC}_{50}$ values to $\mathrm{PE}$ in the OVX were significantly lower compared to the control and OVXE groups (Table 4). The sensitivity of these $\mathrm{PE}$ concentration-response curves in the three groups was enhanced at low concentrations by treatment with $100 \mu \mathrm{M}$ L-NAME, a nitric oxide synthase inhibitor (Fig. 2B). The $\mathrm{EC}_{50}$ value in the OVX group was significantly less than those in the OVXE and control groups. The PE concentration-response curves following treatment with L-NAME were not shifted with the introduction of $100 \mathrm{nM} \mathrm{BMY} \mathrm{7378,} \mathrm{an} \alpha_{\mathrm{i}}$-adrenoceptor antagonist. The contractile response of the arterial smooth muscle to $1 \mu \mathrm{M}$ PE following L-NAME and BMY7378 treatment was significantly higher in the OVX group $(141.6 \pm 14.4 \%)$ compared with both the control $(65.9 \pm$ $21.1 \%)$ and OVXE $(32.8 \pm 19.5 \%)$ groups (Fig. 2C). No significant difference was detected in the 


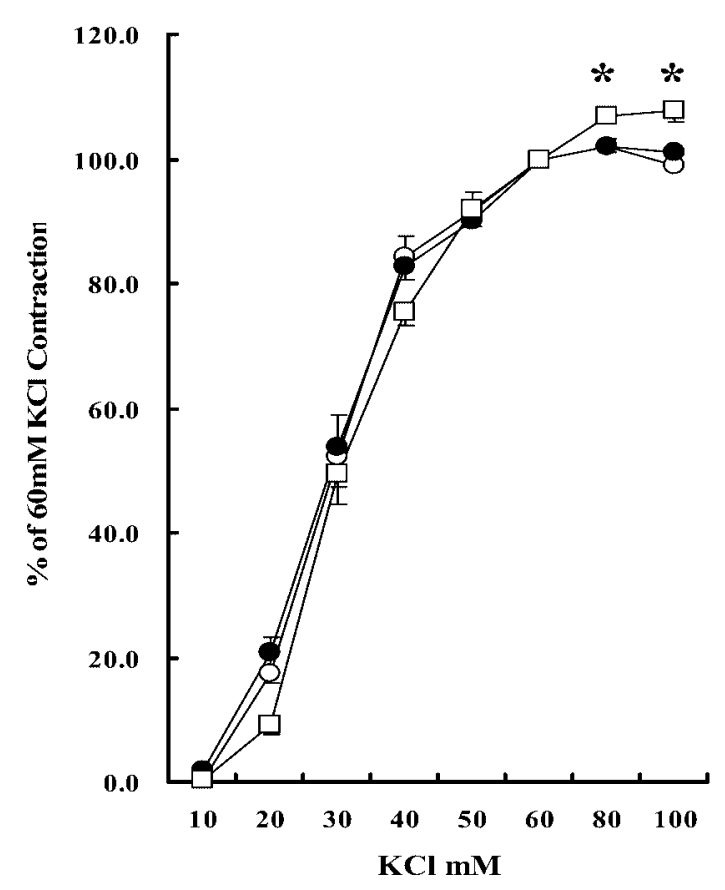

Fig. 1. Contractile response curves for $\mathrm{KCl}$ in renal artery preparations isolated from the three groups. Control: sham operated rats (C); OVX: ovariectomized rats (O); OVXE: ovariectomized rats treated with $17 \beta$-estradiol for 2 weeks $(\square)$. *, Significant difference from Control $(P<0.05)$.

$\mathrm{EC}_{50}$ values of the contractile responses after the treatment with BMY7378 between the three groups.

\section{Rate of relaxation following PE-induced contraction}

The rate of relaxation following a contraction was measured as the time required to reach $50 \%$ of the maximum tension $\left(\mathrm{T}_{1 / 2}\right)$ after the $\mathrm{PE}$ was washed out of the bath. This value was significantly higher in the OVX group ( $85 \pm 13 \mathrm{sec}$ ) compared with the control group (47 \pm 4 sec) as shown in Fig. 3A. The $T_{1 / 2}$ value of the relaxation in the OVXE group (47 $\pm 17 \mathrm{sec}$ ) was similar to the control group. Following treatment with $100 \mu \mathrm{M}$ L-NAME, $\mathrm{T}_{1 / 2}$ values were prolonged in all groups. The $\mathrm{T}_{1 / 2}$ value in the OVX group $(137 \pm 19 \mathrm{sec})$ was significantly higher than that of the control group $\left(66 \pm 10 \mathrm{sec}\right.$ ) (Fig. $3 \mathrm{~B}$ ). In contrast, the $\mathrm{T}_{1 / 2}$ value of the relaxation in the OVXE group $(84 \pm 20 \mathrm{sec})$ was similar to that of the control group. To ensure the validity of $T_{1 / 2}$ as a measure of the relaxation rate, the exponential components of these processes were examined. The slopes were almost the same: -3.4 in controls, -3.7 in OVX and -3.6 in OVXE groups, respectively. While this indicates that the three groups have the same relaxation component, the $\mathrm{T}_{1 / 2}$ value in the OVX group was significantly different to that in both the control and OVXE groups. 
A

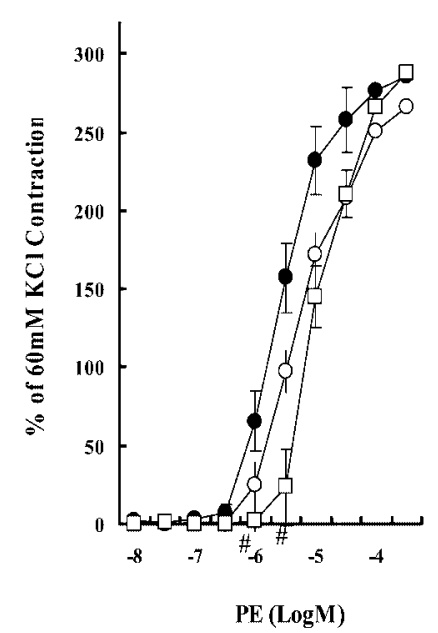

B

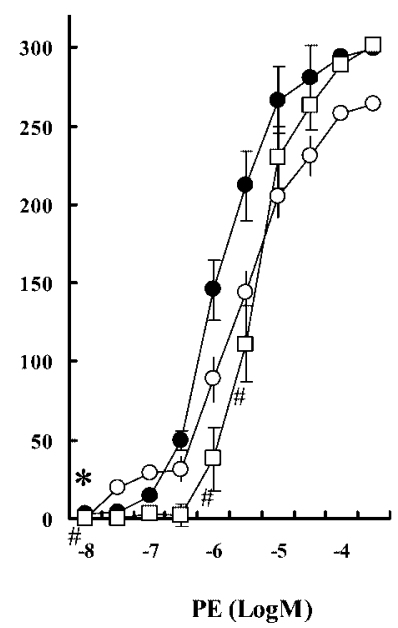

$\mathrm{C}$

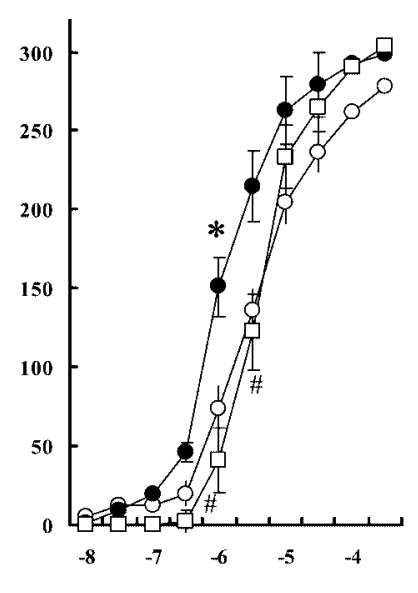

PE (LogM)

Fig. 2. A: Phenylephnine (PE) contractile-response curves in renal artery preparations isolated from the three groups. B: Phenylephnine (PE) contractile-response curves in renal artery preparations isolated from the three groups after treatment with $100 \mu \mathrm{M} \mathrm{L}-\mathrm{NAME} .{ }^{*}$, Significant difference from control $(P<0.05)$. \#, Significant difference from OVX $(P<0.05)$. C: Phenylephnine (PE) contractile-response curves in renal arteries isolated from the three groups after treatment with $100 \mu \mathrm{M}$ L-NAME and $100 \mathrm{nM}$ BMY7378. Control: sham operated rats (C); OVX: ovariectomized rats (O); OVXE: ovariectomized rats treated with $17 \beta$-estradiol for 2 weeks $(\square)$. *, Significant difference from control $(P<0.05)$. ", Significant difference from OVX $(P<0.05)$.

Table 4. Effects of L-NAME and BMY7378 on the $\mathrm{EC}_{50}(\mu \mathrm{M})$ values to phenylephrine (PE) in renal artery preparations isolated from control, OVX and OVXE animals

\begin{tabular}{lccr}
\hline Groups & $\begin{array}{c}\text { Control } \\
(\mathrm{n}=6)\end{array}$ & $\begin{array}{c}\text { OVX } \\
(\mathrm{n}=6)\end{array}$ & $\begin{array}{c}\text { OVXE } \\
(\mathrm{n}=6)\end{array}$ \\
\hline PE & $10.8 \pm 5.5$ & $4.1 \pm 1.2^{*}$ & $16.2 \pm 5.6^{\#}$ \\
PE with L-NAME & $6.2 \pm 3.9$ & $1.4 \pm 0.3^{*}$ & $6.3 \pm 1.4^{\#}$ \\
PE with L-NAME and BMY7378 & $5.7 \pm 2.9$ & $1.5 \pm 0.3^{*}$ & $6.5 \pm 1.7^{\#}$ \\
\hline
\end{tabular}

Values are mean \pm SEM. * Significantly different from control $(P<0.05)$. \#, Significantly different from OVX $(P<0.05)$.

\section{Discussion}

In the current study we have investigated the effect of estrogen on both the contractile and relaxation activity in the renal artery isolated from OVX rats. Our results revealed that the PE concentration responses curve in OVX rat preparations slightly but significantly shifted to the left compared to the response in control perparations, and that the response was prevented by continuous administration of $17 \beta$-estradiol for 2 weeks. After treatment with $100 \mu \mathrm{M}$ L-NAME, the $\mathrm{EC}_{50}$ values of the $\mathrm{PE}$ concentration response curves decreased in the three groups, and it was still less in the OVX group than in the control and in OVXE groups. These results have demonstrated that ovariectomy affected PE-induced contraction of renal artery smooth muscle 

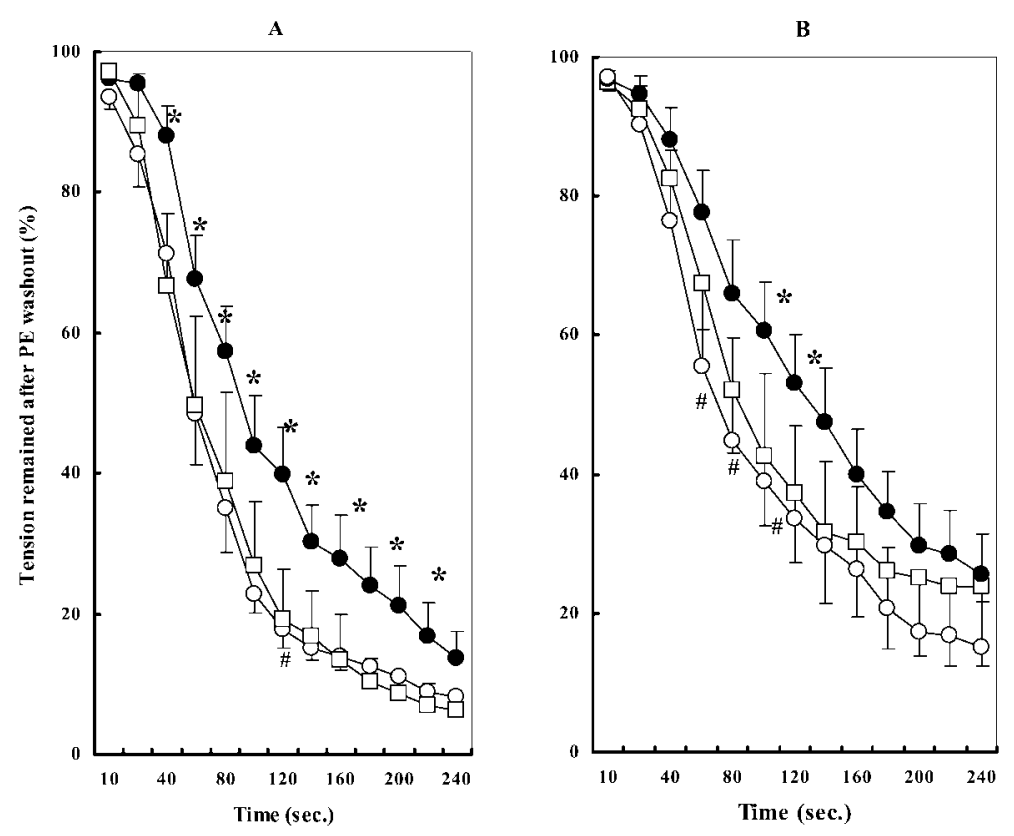

Fig. 3. Time profiles of relaxation after washout PE of renal artery preparations isolated from the three groups in the absence (A) or presence of $100 \mu \mathrm{M}$ L-NAME (B). Control: sham operated rats $(\mathrm{C})$; OVX: ovariectomized rats $(\mathrm{O})$; OVXE: ovariectomized rats treated with $17 \beta$-estradiol for 2 weeks $(\square)$. *, Significant difference from control $(P<0.05)$. \#, Significant difference from OVX $(P<0.05)$.

slightly but significantly, and that the administration of $17 \beta$-estradiol partly prevented this affect in the OVX group. Furthermore, $17 \beta$-estradiol treatment significantly prevented the alterations of the relaxation as shown in Fig. 3. In order to identify whether the relaxation occurred via the endothelium, acetylcholine $(\mathrm{ACh})$ was applied to the preparations. There was no significant difference in the ACh-induced relaxation between the three groups (data not shown), suggesting that renal arteries isolated from the three groups were endothelium intact preparations. In addition, we found that differences between the artery relaxation rates were not completely eliminated by L-NAME in all groups in this study. Therefore, our results suggest that $17 \beta$-estradiol regulates renal artery contractile responses via alteration of $\mathrm{Ca}^{2+}$ transport systems, which also may be independent of the NO relaxation factor. After wash out of PE, a remarkably slower rate of relaxation was measured in preparations derived from the OVX preparations relative to those from both control and OVXE preparations. This reduced rate of relaxation could either be the result of lower intracellular $\mathrm{Ca}^{2+}$ extrusion or the result of an increase in the inward $\mathrm{Ca}^{2+}$ leak. An alternative explanation for the diminished relaxation rate following PE-induced contractions is that the rate of PE removal after washing is lower in the OVX group consequent to decreased dissociation or degradation of the PE. It is possible that $\mathrm{Ca}^{2+}$ pump activity in the smooth muscle of the renal arteries from the OVX rats was reduced to a larger extent than that in the control rats.

It has been reported that activation of $\alpha$-adrenoceptors increases the concentration of 
intracellular $\mathrm{Ca}^{2+}$, which in turn produces contraction of smooth muscle cells (Leech and Faber, 1996). We have already demonstrated that prazosin, an $\alpha_{1}$ adrenoceptor blocker, inhibited norepinephrine-induced contraction in renal arteries, and that nifedipine, a $\mathrm{Ca}^{2+}$ antagonist, also suppressed utilization of extracellular $\mathrm{Ca}^{2+}$ (Inazu et al., 1991). Three subtypes of $\alpha_{1^{-}}$ adrenoceptors have been classified on the basis of pharmacological and molecular biology criteria (MacDougall et al., 2006), and are referred to as $\alpha_{1 \mathrm{~A}}, \alpha_{1 \mathrm{~B}}$ and $\alpha_{1 \mathrm{D}}$ receptors. BMY7378 is a highly selective antagonist of the $\alpha_{1 \mathrm{D}}$-adrenoceptor subtype (Goetz et al., 1995) and can be used to distinguish $\alpha_{1}$-adrenoceptor subtypes present in different tissues. Studies measuring mRNA have demonstrated that the rat renal artery expresses the $\alpha_{1 \mathrm{D}}$-adrenoceptor subtype (Piascik et al., 1994) at a level comparable to that in the aorta (Suzuki et al., 1997). The $\alpha_{1 D^{-}}$ adrenoceptor significantly mediated rat renal arterial diameter (Villalobos-Molina et al., 1997). Our previous report (Tajima et al., 2002) showed that the $\alpha_{1 \mathrm{D}}$-adrenoceptor was related to PEinduced hyperreactive contraction in diabetes. There was a slight inhibition by $100 \mathrm{nM}$ BMY7378 at low PE concentration in the control group. However, $100 \mathrm{nM} \mathrm{BMY7378} \mathrm{did} \mathrm{not}$ affect the PE concentration response curves in the three groups after treatment with $100 \mu \mathrm{M} \mathrm{L}$ NAME.

Studies have shown that estrogen may regulate vascular tone in the cerebral artery by shifting cyclooxygenase-1 (COX-1)-dependent vasodilatation or vasoconstriction (Ospina $e$ t al., 2003; Jun et al., 1998). Indomethacine significantly, albeit slightly, affected contractile responses to $\mathrm{PE}$ in the current investigation; however, no differences were detected among the three groups (data not shown). This effect may be attributable to the inhibition of the COXdependent release of $\mathrm{PGI}_{2}$. Studies have reported that estrogen increases the contraction caused by $\alpha_{2}$-adrenoceptor activation in the presence of clonidine, an $\alpha_{2}$-adrenoceptor agonist (Tejera et al., 1999). Moreover, Mihmanli et al. (2002) reported that in the human renal artery, vascular tone is dependent on estrogen levels. We hypothesize that the effects of $17 \beta$-estradiol on renal arterial tone may regulate contraction through $\mathrm{Ca}^{2+}$ pump activity as shown in Fig. 3 . While $17 \beta$-estradiol enhanced sensitivity to norepinephrine in the rabbit aorta with an intact endothelium (Miller et al., 1990), there is also a report that in contrast $17 \beta$-estradiol induced inhibition of the PE-contractile response of vessels in female dogs (Karanian et al., 1996). Our results with respect to the OVXE group are related to the latter report. However, other studies noted that the effects of $17 \beta$-estradiol on vessels display 'regional heterogeneity effects' (Tatchum-Talom et al., 2002). Explanations regarding the protective effects of $17 \beta$-estradiol have been offered by several authors on the basis of the NO or NOS-dependent pathway (Beyer et al., 2001; Geary et al., 2000; McNeill et al., 1999) and $\mathrm{Ca}^{2+}$ transport mechanisms (Crews et al., 1999; Murphy et al., 2000; Tep-areenan et al., 2003). Consequently, we hypothesized that the effects of $17 \beta$-estradiol may influence several pathways of the contractile system in vascular smooth muscle. The current investigation revealed a significantly lower relaxation rate following washout of PE in the OVX group in comparison with the control group before and after treatment with L-NAME. This finding indicated that the relaxation effect of estrogen is not completely related to the NO or NOS dependent mechanism. Therefore, the relaxation effect of estrogen may be associated with the $\mathrm{Ca}^{2+}$ regulation system as well as with NO release in the OVX rats. These effects could be partially recovered upon $17 \beta$-estradiol treatment in the OVXE 
(Fig. 3).

Several investigators reported that the relaxation effects of $17 \beta$-estradiol in coronary arteries of pigs (Murphy et al., 1999), vascular smooth muscle cells (Murphy et al., 2000) and in the aorta of rats (Tep-areenan et al., 2003) occurred via inhibition of $\mathrm{Ca}^{2+}$ influx. Moreover, several studies noted that the effects of $17 \beta$-estradiol involved the modulation of $\mathrm{Ca}^{2+}$-activated $\mathrm{K}^{+}$ channels (Node et al., 1997; Rosenfeld et al., 2000). Tetraethylammonium (TEA), a $\mathrm{K}^{+}$channel inhibitor, did not affect our results (data not shown). The present investigation demonstrated the hyperreactivity of contractile responses to $\mathrm{KCl}$ in the OVXE rats. The contractile response to $\mathrm{KCl}$ is caused by an increased $\mathrm{Ca}^{2+}$ influx in the smooth muscle of OVXE rats relative to that in the control and OVX rats as shown in Figs 1 and 2.

Body weight exhibited meaningful albeit slight recovery; in contrast, uterine weight was not restored by administration of $17 \beta$-estradiol. The $17 \beta$-estradiol treatment, which was initiated one month post-ovariectomy, was continued at $17 \mu \mathrm{g}$ for 2 weeks, which may, in part, account for our findings. Several investigations described implementation of $17 \beta$-estradiol treatment concomitant with ovariectomy; furthermore, this regime led to normalization of body and uterine weights of ovariectomized rats (Davidge et al., 1998; Ospina et al., 2003; Teede $e$ t al., 2001). Alteration of fatty acid composition in the uterus of OVX rats was significantly different from that in control rats and the changes were slightly reduced by treatment with $17 \beta$-estradiol (Table 2). This phenomenon might be correlated with the dosage and treatment with $17 \beta$ estradiol in this study. Results from the current study suggested that estrogen regulates $\mathrm{Ca}^{2+}$ transport systems as well as NO release.

\section{Acknowledgements}

Dr. Budbazar Enkhjargal was a visiting research fellow from Ulaanbaatar Medical University in Mongolia at Faculty of Health Sciences, Showa University, Yokohama, Japan. This work was partly supported by the Smoking Research Foundation.

\section{References}

Beyer, M.E., Yu, G., Hanke, H. and Hoffmeister, H.M. (2001). Acute gender-specific hemodynamic and inotropic effects of $17 \beta$-estradiol on rats. Hypertension 38: 1003-1010.

Crews, J.K. and Khalil, R.A. (1999). Gender-specific inhibition of $\mathrm{Ca}^{2+}$ entry mechanisms of arterial vasoconstriction by sex hormones. Clin. Exp. Pharmacol. Physiol. 26: 707-715.

Davidge, S.T. and Zhang, Y. (1998). Estrogen replacement suppresses a prostaglandin H synthasedependent vasoconstrictor in rat mesenteric arteries. Circ. Res. 83: 388-395.

Geary, G.G., Krause, D.N. and Duckles, S.P. (2000). Estrogen reduces mouse cerebral artery tone through endothelial NOS- and cyclooxygenase-dependent mechanisms. Am. J. Physiol. 279: H511-H519.

Goetz, A.S., King, H.K., Ward, S.D., True, T.A., Rimele, T.J. and Saussy, D.L.Jr. (1995). MY 7378 is a selective antagonist of the D subtype of $\alpha_{1}$-adrenoceptors. Eur. J. Pharmacol. 272: R5-R6.

Hashimoto, M., Shinozuka, K., Gamoh, S., Tanabe, Y., Hossain, M.S., Kwon, Y.M., Hata, N., Misawa, Y., Kunitomo, M. and Masumura, S. (1999). The hypotensive effect of docosahexaenoic acid is associated with the enhanced release of ATP from the caudal artery of aged rats. J. Nutr. 129: 
70-76.

Hulley, S., Grady, D., Bush, T., Furberg, C., Herrington, D., Riggs, B. and Vittinghoff. E. (1998). Randomized trial of estrogen plus progestin for secondary prevention of coronary heart disease in postmenopausal women. Heart and Estrogen/progestin Replacement Study (HERS) Research Group. JAMA 280: 605-613.

Inazu, M., Sakai, Y. and Homma, I. (1991). Contractile responses and calcium mobilization in renal arteries of diabetic rats. Eur. J. Pharmacol. 203: 79-84.

Jun, S.S., Chen, Z., Pace, M.C. and Shaul, P.W. (1998). Estrogen upregulates cyclooxygenase-1 gene expression in ovine fetal pulmonary artery endothelium. J. Clin. Invest. 102: 176-183.

Karanian, J.W. and Ramwell, P.W. (1996). Effect of gender and sex steroids on the contractile response of canine coronary and renal blood vessels. J. Cardiovasc. Pharmacol. 27: 312-319.

Leech, C.J. and Faber, J.E. (1996). Different $\alpha$-adrenoceptor subtypes mediate constriction of arterioles and venules. Am. J. Physiol. 270: H710-H722.

Macdougall, I.J. and Griffith, R. (2006). Selective pharmacophore design for $\alpha_{1}$-adrenoceptor subtypes. $J$. Mol. Graph. Model. 25: 146-157.

McNeill, A.M., Kim, N., Duckles, S.P., Krause, D.N. and Kontos, H.A. (1999). Chronic estrogen treatment increases levels of endothelial nitric oxide synthase protein in rat cerebral microvessels. Stroke 30: 2186-2190.

Mihmanli, I., Mihmanli, V., Kantarci, F., Albayram, M.S., Atakir, K., Cantasdemir, M. and Akman, C. (2002). Effects of oophorectomy and hormone replacement therapy on the pulsatility indices of hepatic and renal arteries. J. Ultrasound Med. 21: 367-373.

Miller, V.M. and Vanhoutte, P.M. (1990). $17 \beta$-Estradiol augments endothelium-dependent contractions to arachidonic acid in rabbit aorta. Am. J. Physiol. 258: R1502-R1507.

Murphy, J.G. and Khalil, R.A. (1999). Decreased $\left[\mathrm{Ca}^{2+}\right]_{\mathrm{i}}$ during inhibition of coronary smooth muscle contraction by $17 \beta$-estradiol, progesterone, and testosterone. J. Pharmacol. Exp. Ther. 291: 4452.

Murphy, J.G. and Khalil, R.A. (2000). Gender-specific reduction in contractility and $\left[\mathrm{Ca}^{2+}\right]_{\mathrm{i}}$ in vascular smooth muscle cells of female rat. Am. J. Physiol. 278: C834-C844.

Node, K., Kitakaze, M., Kosaka, H., Minamino, T., Sato, H., Kuzuya, T. and Hori, M. (1997). Roles of NO and $\mathrm{Ca}^{2+}$-activated $\mathrm{K}^{+}$channels in coronary vasodilation induced by $17 \beta$-estradiol in ischemic heart failure. FASEB J. 11: 793-799.

Ospina, J.A., Duckles, S.P. and Krause, D.N. (2003). 17beta-estradiol decreases vascular tone incerebral arteries by shifting COX-dependent vasoconstriction to vasodilation. Am. J. Physiol. 285: H241$\mathrm{H} 250$.

Piascik, M.T., Smith, M.S., Soltis, E.E. and Perez, D.M. (1994). Identification of the mRNA for the novel $\alpha_{1 \mathrm{D}}$-adrenoceptor and two other $\alpha_{1}$-adrenoceptors in vascular smooth muscle. Mol. Pharmacol. 46: $30-40$.

Rosenfeld, C.R., White, R.E., Roy, T. and Cox, B.E. (2000). Calcium-activated potassium channels and nitric oxide co-regulate estrogen-induced vasodilation. Am. J. Physiol. 279: H319-H328.

Suzuki, F., Miyamoto, S., Takita, M., Oshita, M., Watanabe, Y., Kakizuka, A., Narumiya, S., Taniguchi, T. and Muramatsu, I. (1997). Cloning, functional expression and tissue distribution of rabbit $\alpha_{1 d^{-}}$ adrenoceptor. Biochim. Biophys. Acta. 1323: 6-11.

Tajima, H., Sakai, Y., Maruyama, Y. and Homma, I. (2001). Characteristics of the contractile responses in renal arteries from diabetic rats. Showa Univ. J. Med. Sci. 13: 125-133.

Tatchum-Talom, R., Martel, C. and Marette, A. (2002). Influence of estrogen on aortic stiffness and endothelial function in female rats. Am. J. Physiol. 282: H491-H498.

Tep-areenan, P., Kendall, D.A. and Randall, M.D. (2003). Mechanisms of vasorelaxation to $17 \beta$-oestradiol in rat arteries. Eur. J. Pharmacol. 476: 139-149.

Teede, H., van der Zypp, A. and Majewski, H. (2001). Gender differences in protein kinase G-mediated 
vasorelaxation of rat aorta. Clin. Sci. (Lond.) 100: 473-479.

Tejera, N., Balfagon, G., Marin, J. and Ferrer, M. (1999). Gender differences in the endothelial regulation of $\alpha_{2}$-adrenoceptor-mediated contraction in the rat aorta. Clin. Sci. (Lond.) 97: 19-25.

Tolbert, T. and Oparil, S. (2001). Cardiovascular effects of estrogen. Am. J. Hypertens. 14: 186S-193S.

Veille, J.C., Li, P., Eisenach, J.C., Massmann, A.G. and Figueroa, J.P. (1996). Effects of estrogen on nitric oxide biosynthesis and vasorelaxant activity in sheep uterine and renal arteries in vitro. Am. J. Obstet. Gynecol. 174: 1043-1049.

Villalobos-Molina, R., Lopez-Guerrero, J.J. and Ibarra, M. (1997). Alpha 1D- and alpha 1A-adrenoceptors mediate contraction in rat renal artery. Eur. J. Pharmacol. 322: 225-227.

Zhang, L. and Kosaka, H. (2002). Sex-specific acute effect of estrogen on endothelium-derived contracting factor in the renal artery of hypertensive Dahl rats. J. Hypertens. 20: 237-246. 